\title{
ЭТИКЕТНЫЕ ФОРМЫ ПРИВЕТСТВИЯ В РУССКОЙ И КУМЫКСКОЙ ЛИНГВОКУЛЬТУРАХ
}

\section{ETIQUETTE GREETING FORMS IN RUSSIAN AND KUMYK LINGUISTIC CULTURES}

\section{Aybatyrova N. Gadzhiakhmedov}

Summary: The article considers the general and idioethic features of etiquette forms of greeting in Russian and Kumyk linguistic cultures. Greetings in both linguistic cultures refer to those elements of speech etiquette that are intended mainly to mark social relations established within the framework of a communication act. With the similarity of the communicative behavior of Russians and Kumyks in the greeting situation, some differences are distinguished: a) Russian greetings are distinguished by greater expressiveness than Kumyk ones; b) in the Kumyk language, the most common formulas of greetings are greetings; c) in the Kumyk language there are no equivalents of some Russian stylistically colored forms of greetings.

Keywords: greeting, speech etiquette, questions-greetings, linguoculturology, Kumyk language, Russian language.

\author{
Айбатырова Муслимат Абдуллаевна \\ к.филол.н., старший преподаватель, Дагестанский \\ государственный аграрный университет, г. Махачкала \\ aybatyrova67@mail.ru \\ Гаджиахмедов Нурмагомед Эльдерханович \\ Д.филол.н., профессор, Дагестанский государственный \\ университет, г. Махачкала \\ nur1@yandex.ru
}

Аннотация: В статье рассматриваются общие и идиоэтнические особенности этикетных форм приветствия в русской и кумыкской лингвокультурах. Приветствия в обоих лингвокультурах относятся к тем элементам речевого этикета, которые предназначены главным образом для маркировки социальных отношений, устанавливаемых в рамках коммуникативного акта. При сходстве коммуникативного поведения русских и кумыков в ситуации приветствия выделяются некоторые различия: а) русские приветствия отличаются большей экспрессивностью, чем кумыкские; б) в кумыкском языке наиболее распространенными формулами приветствий являются вопросыприветствия; в) в кумыкском языке отсутствуют эквиваленты некоторых русских стилистически окрашенных форм приветствий.

Ключевые слова: приветствие, речевой этикет, вопросы-приветствия, лингвокультурология, кумыкский язык, русский язык.
$\Pi$ риветствие является одним из универсальных средств, регулирующих поведение человека в обществе. Этикет свойственен всем народам и отражает национальную специфику общения каждой нации [6, с. 18]. Приветствие относится к тем элементам речевого этикета, которые предназначены главным образом для маркировки социальных отношений, устанавливаемых в рамках коммуникативного акта. Эти готовые формулы общения задают этикетный тон всему разговору, определяя ситуацию, набор дифференциальных признаков участников диалога и т. д.

В рамках данного исследования нами предпринята попытка путем сопоставительного исследования русских и кумыкских формул приветствия выявить особенности этно-национальной специфики этикетных форм приветствий в разноструктурных русском и кумыкском языках. Несмотря на имеющиеся исследования проблема

В исследуемых нами лингвокультурах этическую ценность приветствия определяют следующие пословицы: Адамны саламын алмагъанны адамлыгъы ёкъ. «Человек, не отвечающий на приветствие, не имеет достоинства». Салам булан сёз башлар. «Разговор начинается с приветствия». Саламы нечик буса, жавабы да шолай // Каков привет, таков и ответ. Как следует из приведенных пословиц, приветствию в русской и кумыкской коммуникативных культурах придается особое значение: приветствие характеризует степень культуры человека.

В кумыкской лингвокультуре считается, что приветствие, как и всякое благое, доброе дело, исходит от Аллаха, поэтому отсутствие ответа на приветствие расценивается как невежество, слабость, зло. Кумыкская народная мудрость гласит: Салам Аллагьны саламыдыр: душманынг болса да, салам бер ва саламын ал. «Приветствие - от Аллаха, поэтому даже с врагом здоровайся и прими его приветствие». В связи с этим хочется обратить внимание еще на одну паремию, в которой особо подчеркивается важность принятия приветствия: Салам бермек - сюннет, салам алмакъ - парз. «Приветствовать желательно, принять приветствие обязательно».

У русских и кумыков, как и у других народов, есть свои специфические правила и формулы приветствия. Прежде всего, человеку, с которым здороваются, смотрят дружелюбно и приветливо в лицо, что является показателем доброжелательности и отсутствия агрессии. Согласно пословичной картине мира кумыков, определить характер человека можно по тому, как он здоровается, по одному слову, произнесенному им: Яхшы адам 
да, яман адам да - саламындан белгили. «И хорошего человека, и плохого человека можно определить по тому, как он здоровается». И еще кумыки говорят: Ярыкъ адамны саламы юрекге къуват салар. «Приветствие искреннего человека силы прибавляет».

Любое приветствие содержит скрытую форму пожелания. Универсальное русское приветствие Зәравствуйте! содержит пожелание здоровья тому, с кем вы здороваетесь. Кумыкское приветствие Салам алейкум!, заимствованное из арабского языка, содержит пожелание мира. Однако кумыки не осознают содержание этого приветствия как «мир вам». Для них это приветствие, соответствующее содержанию слова «здравствуйте», хотя «Кумыкско-русский словарь» наряду со значением «здравствуйте», называет и значение «мир вам» [1, с. 472; 4, с. 80].

Исконно-кумыкским приветствием является Эсен де бол, аман да! «Будь здоровым, благополучным и невредимым». В этой формуле приветствия слова эсен и аман являются семантическими синонимами: отличие заключается в том, что только аман содержит семантический оттенок «невредимый» [см.: 1, с. 32].

Основной формой приветствия в кумыкской коммуникативной культуре является Салам алейкум! «Мир тебе!» Эта формула приветствия является общим для всех народов, исповедующих Ислам. До недавнего времени это приветствие имело в кумыкской речевой культуре гендерное ограничение: данную формулу приветствия использовали только мужчины. В последние годы под влиянием восточной культуры и женщины стали использовать данную этикетную формулу приветствия в разных ситуациях речи. Но пока еще это явление не получило широкого распространения среди женщин.

Еще одно изменение, которое произошло недавно в кумыкском речевом этикете: до недавнего времени кумыки использовали формулу приветствия Ассаламу алейкум! и Салам алейкум! только при встрече, а теперь, преимущественно верующие люди, используют их и при расставании в значении «будь здоров(а)».

Сейчас в религиозных кругах часто используется расширенная форма традиционного арабского и мусульманского приветствия Ассаламу алейкум! «Мир вам!»: Ассаламу алейкум ва рагьматуллагьи ва баракату «Мир вам и милость Божья и Его благословение». В ответ принято говорить: Ва алейкум ассалам ва рахматуллагьи ва баракату!, что означает: «И вам милость Божья и Его благословение!».

При приветствии множества людей кумыки обычно говорят Ассаламу алейкум, на что один из людей громко от лица всех присутствующих может произнести Ваалей- кум салам!, а остальные тихо произносят то же самое.

В некоторых ситуациях коммуникант, инициирующий приветствие, сначала спрашивает о том, как поживает его собеседник, а затем приветствует, как и положено по речевому этикету. Приведем пример:

[Казим]: Не этип турасыз, атай? Салам алейкум! «Как вы поживаете, отец? Мир вам!»

[Хасболат]: Ваалейкум салам, гел яшым. Къонакъ бол! «И тебе мир, заходи, сын мой. Будь гостем!»

В русском языке самой распространенной вербальной формой приветствия является: Здравствуй или Здравствуйте! Первый вариант приветствия используется в ситуации общения с близкими людьми, в неофициальной обстановке, а второй вариант - при общении с малознакомыми, в официальной обстановке или при вежливом обращении. В кумыкской речевой этнокультуре используется слово Идирасти!, заимствованное из русского языка. Чаще всего данная форма приветствия используется между женщинами и мужчинами. Мужчины между собой не используют данную формулу приветствия.

Во многих национальных культурах здороваться можно, используя и вопросительные предложения. В зависимости от коммуникативной ситуации в кумыкской этнической культуре используются такие вопросы-приветствия: Не этдинг? «Что делаешь? Куда направился?» Къайтардынгмы? «Возвращаешься?» Къайсылайдыр? «Куда идешь?» Иигеми? «На работу?» Эти вопросы-приветствия используются в коммуникации независимо от времени суток. Подобные вопросы-приветствия встречаются во многих языках. Так, в аварском языке используются такие вопросы-приветствия, как Вач1иневищ вугев? «Идешь?» Г1одорч1унищ ругел? «Сидите?» Хабар-к1алалдайищ? «Общаетесь?» Подобные вопросыприветствия обычно не требуют полных и развернутых ответов. Ни кумыки, ни аварцы ответов на такие вопросы-приветствия и не ждут. Это часть этикетной этнокультуры этих народов. Задавая подобные вопросы, коммуникант старается проявить свое участие в разговоре и заинтересованность в делах собеседника.

Интересным с этнокультурной точки зрения является функционально-семантическая сущность вопросаприветствия Турдунгму? «Встал ли?» или «Турдугъузму?» «Встали ли?», которые имеет временную ограниченность в своем использовании: это вопрос-приветствие используют кумыки только рано утром. На наш взгляд, вставать рано означало находиться в здравии и состоянии чтолибо делать. Постепенно это превратилось в устойчивую формулу приветствия в виде вопроса со значением «Доброе утро! Здравствуйте!». 
При произношении вопросительных этических формул приветствия интонация должна быть теплой и дружелюбной. Если же вы поздороваетесь сухим грубым тоном, то можете запросто обидеть собеседника, а улыбка, напротив, поможет вам поднять настроение собственное и вашего собеседника, при этом обязательно встретьтесь с ним взглядом.

В отличие от кумыкского языка, в русском достаточно много стилистически окрашенных форм приветствия. Стилистически сниженное просторечное приветствие Здорово! представляет собой, с одной стороны, «развернутое пожелание жить здоровым», с другой - является «более сложным за счет наложения квалификативного элемента «здорово живешь», т. е. хорошо» [2, с. 119]. Исследователи отмечают и гендерный характер приветствий Здорово! и Здоров!, относя их к чисто мужским приветствиям, применяемым для нарочитого подчеркивания равенства, фамильярно грубоватой тональности общения, и не характерным для речи женщин [7, с. 60].

К стилистически сниженным относятся в русском языке и формулы приветствия в ежедневном общении у молодежи Привет!, Приветик!, которым также нет соответствий в кумыкском языке.

Русская речевая культура характеризуется не только наличием стилистически сниженных (ограниченных) форм приветствия, но и стилистически повышенных формул типа Приветствую вас! Рад вас приветствовать! Разрешите приветствовать вас! Честь имею (устар.) приветствовать вас. Эти формулы приветствия отличаются тем, что в них присутствуют компоненты уважительности. Они используются обычно людьми старшего (реже среднего) поколения в официальной обстановке с формами вы-общения [7, с. 47]. В кумыкской коммуникативной культуре не наблюдается такого разнообразия в выборе формул приветствия для использования в разных стилях речи. Стилистически сниженная форма приветствия отсутствует, и всех, независимо от их возраста и социального статуса, принято приветствовать Ассаламу алейкум! или Эсен де бол, аман да!

Нередко в общении людей возникает необходимость несколько раз в течение дня встречаться друг с другом. При этом обмениваться приветствием каждый раз в сопоставляемых лингвокультурах не принято. Для этого существуют «обтекаемые фразы», которые сопровождают определенную мимику и жесты: улыбку, кивок головой. Для русского языка это выражение типа Мы уже виделись [8, с. 122]. В кумыкском языке для этих целей используются фразы: Не этдинг? «Что делаешь?» или Къайтардынгмы? «Уходишь?» «Возвращаешься?» в зависимости от ситуации речи.

По кумыкскому этикету сидящий в помещении муж- чина обязан встать, сделать шаг вперед и первым приветствовать женщину, когда она входит, словами Гюн яхшы болсун «Добрый день». Знакомой женщине мужчина может пожать руку. При этом в кумыкской лингвокультуре в отличие от русской мужчина первым протягивает руку женщине.

В обоих лингвокультурах есть приветствия, употребляемые в определенное время суток. Ср. Гюн яхшы болсун! // Добрый день! Ахшамыгъыз яхшы болсун! // Добрый вечер! Танг яхшы болсун! // Доброе утро! Геч яхшы болсун! // Доброй ночи. На наш взгляд, приветствия, связанные с границами между временами суток, в кумыкской языковой картине мира появились под влиянием русского языка. Однако следует отметить, что в кумыкском приветствии Танг яхшы болсун! // Доброе утро! нет названия этого времени суток - эртен «утро». В приветствие включено слово танг «рассвет, заря». Видимо, это следует объяснить тем, что кумыки занимались скотоводством и земледелием, и эта деятельность людей начинается с рассвета.

В кумыкском приветствии Геч яхшы болсун! // Доброй ночи! также нет лексемы гече «ночь». В этой формуле приветствия вместо слова гече «ночь» кумыки используют слово геч «поздно, позднее время». Хотя необходимо отметить и то, что слово гече «ночь» используется кумыками в этой же речевой формуле с аффиксами притяжательности 1 и 2 лица единственного и множественного числа: Геченг яхшы болсун! букв. «Чтобы ночь твоя была доброй» или Гечегиз яхшы болсун! букв. «Чтобы ваша ночь была доброй!» Однако последние две формулы являются не формулами приветствия, а формулами прощания.

В русском речевом этикете «доброе утро» рекомендуется говорить в промежуток с 8 до 11 часов. Для кумыков утро - это часть суток с рассвета до 8 часов утра. Однако различия заключаются не только в этом. Особенность русской языковой картины мира состоит в том, что время суток в ней определяется деятельностью, которая его наполняет [3, с. 28]. Утро в русском языковом сознании начинает день и дневную деятельность человека [5, с. 41]. Приветствие Доброе утро! представляет собой нечто вроде поздравления с пробуждением. Так приветствуют человека, который только что пробудился, но еще не начал свою деятельность. Как в русском, так и в кумыкской лингвокультуре приветствия Доброе утро! и Танг яхшы болсун! «уместно только непосредственно после пробуждения, пока участники коммуникации еще не приступили к своей дневной деятельности» [9, с. 22].

Пожелание-приветствие Хорошего вам дня, появилось недавно в русском языке под влиянием западных языков. С. Г. Тер-Минасова распространение этой формулы связывает «с влиянием западных языков: она звучит как калька французского Bonne journee!» [9, с. 22]. 
Данному приветствию-пожеланию в кумыкском языке соответствует Гюн яхшы болсун «Хорошего вам дня».

Кратким вариантом приветствия Ассаламу алейкум является Салам! «Привет!» и используется лишь в неофициальной сфере общения.

Выбор той или иной формулы приветствия зависит и от того, знакомы участники коммуникативной ситуации друг с другом или нет. Если коммуниканты незнакомы, то выбор той или иной формы приветствия зависит от возраста адресата. К ровеснику или младшему по возрасту кумыки обращаются с приветствием Салам! (к мужчине). Если же участники акта коммуникации знакомы, то все зависит от степени знакомства: друзья часто приветствуют друг друга словом Салам! «Привет!», так же приветствуют и близких по возрасту родственников и знакомых.

В кумыкском языке нет разговорных форм приветствия типа русского Привет! Приветик! Салютик! Н.И. Формановская дает тщательный анализ русских приветствий [1987]. По мнению автора, Привет! — выражение фамильярно-дружеского расположения между людьми при встрече. «Добрый день!» - это выражение является эквивалентом приветствия Здравствуй(-те).
Употребляется оно реже, но в некоторых случаях бывает особенно удобным, если здоровающемуся надо обратиться в формах Здравствуй! - Здравствуйте!

Но каждый язык обладает своим фондом этикетных формул. В русском языке они зависят от степени близости общающихся людей, возраста, пола, от того, кем является приветствуемый человек и чем он занят в данный момент. Особенностью русского речевого этикета является также употребление личных местоимений, в которых выражается статус собеседника, таких как «ты» и «Вы». А в кумыкском речевом этикете при обращении к собеседнику личные местоимения, как правило, не употребляются.

Таким образом, существуют национально-специфические требования к соблюдению речевого этикета в конкретных стандартных ситуациях общения. При сходстве коммуникативного поведения русских и кумыков в ситуации приветствия выделяются некоторые различия, которые кратко можно сформулировать так: а) русские приветствия отличаются большей экспрессивностью; б) в кумыкском литературном языке отсутствуют эквиваленты некоторых русских стилистических окрашенных форм приветствий.

\section{ЛИТЕРАТУРА}

1. Бамматов Б.Г., Гаджиахмедов Н.Э. Кумыкско-русский словарь. - Махачкала, 2013. - 523 с.

2. Бобровская Г.В. Будь здоров! Здорово живешь! // Русская речь. — 2002. - № 1. — С. 118 - 120.

3. Бортникова Т.Г. Отношение ко времени как отражение этнического сознания // Исторические, философские, политические и юридические науки, культурология и искусствоведение. Вопросы теории и практики Тамбов: Грамота, 2017. № 5(79). С. $27-32$.

4. Гаджиахмедов Н.Э., Магомедова М.М. Приветствие и прощание в русской и кумыкской коммуникативных культурах // Известия дагестанского государственного педагогического университета. 2010. № 2 (11). — С. 79-82

5. Зализняк А.А., Шмелев А.Д. Время суток и виды деятельности // Ключевые идеи русской языковой картины мира: Сб. ст. — М.: Языки славянской культуры, 2005. С. 39-51.

6. Формановская Н.И. Речевой этикет в русском общении. Теория и практика - М.: ВК, 2009. - 334 с.

7. Формановская Н.И. Вы сказали «Здравствуйте!» (Речевой этикет в нашем общении). — М.: Знание, 1987. — 160 c.

8. Формановская Н.И. Речевой этикет. Русско-немецкие соответствия. Справочник. — М.: Высшая школа, 1989. — 96 с.

9. Шмелев А.Д. Можно ли понять русскую культуру через ключевые слова русского языка? // Ключевые идеи русской языковой картины мира: Сб. ст. — М.: Языки славянской культуры, 2005. - С. 17-25.

( А Айбатырова Муслимат Абдуллаевна (aybatyrova67@mail.ru), Гаджиахмедов Нурмагомед Эльдерханович (nur1@yandex.ru), 